\title{
Factors Affecting Quality Teaching and Learning Outcomes in Teacher Education in Sierra Leone
}

\author{
Prince C. Brainard \\ Planning \& Quality Assurance Officer, Freetown Teachers College, Sierra Leone
}

*Corresponding Author: Prince C. Brainard, Planning \& Quality Assurance Officer, Freetown Teachers College, Sierra Leone

\begin{abstract}
The focus of this study was on the factor affecting quality teaching and learning outcomes in teacher education in Sierra Leone.

The UNESCO (2013:p.123), Sierra Leone: Country Status Report on Education, highlighted some negative impacts on the quality of teacher education in the country, which include: (i) courses are theoretical, lacking teaching practice, pedagogical skills components, field trips and laboratories; (ii) programmes are at risk of becoming outdated due to lack of regular review; (iii) teaching methods are inadequate, essentially lecturebased, and exams test mainly cognitive skills and memory; and (iv) most students following TC or HTC Primary training are among the poorer WASSCE performers, which puts the starting level of teachers' competencies at a low level.
\end{abstract}

The declining performance of teaching and learning, coupled with the demands for improved teacher quality in the country also necessitated this study. The study sample comprised 100 participants (40 students, 30 lecturers, 14 administrators, 2 officials from the Education Ministries, 2 officials from the Teaching Service Commission (TSC), two officials from the Tertiary Education Commission (TEC), and ten alumni (past students). Purposive and simple convenience random sampling techniques were used for sampling the targeted population.

The study employed a mixed method approach using both quantitative and qualitative data collection techniques which included questionnaires, interview schedule guides and observation. Data from interviews and some from the questionnaires were qualitatively analyzed, by picking out words and expressions frequently used by the interviewees and organizing them into categories or themes.

The study revealed the following to be the major factors that negatively impacted quality teaching and learning outcomes at the institution: Lack of science laboratory, outdated curricula, absenteeism, lack of recent textbooks and other educational materials, non-coverage of teaching syllabus, inadequate funding, inadequate infrastructural facilities, and poor lecturer motivation.

\section{INTRODUCTION}

\subsection{The Role of Education}

As Kumar (2016:p.1217) noted that:

Education is the key for development of any nation and it depends on the quality of teachers. Knowledge, dedication, quality, professional commitment and motivation of teachers are the factors responsible for quality education and learner achievement. Producing such teachers is a major challenge for governments across the globe today. With the ever-increasing amount of knowledge today, teacher's job has been more challenging in the light of new pedagogical and psychological theories, philosophy, sociology and globalization. Well planned and imaginative Teacher education programmes are required today. Teacher education programme has to be critiqued, studied, reformed, rethought and reoriented today.

Education ensures the acquisition of knowledge and skills that enables individuals to increase their productivity and to improve their livelihoods. Access to quality education is important because of the power of education to reduce poverty, to improve the lives of individuals and groups and to transform society. 
The pivotal role played by education in the development of the person and society cannot be underestimated. UNESCO (2016: p.10) defined this role as:

Increased educational attainment helps transform lives by reducing poverty, improving health outcomes, advancing technology and increasing social cohesion. It can enable individuals to better cope with, and reduce their vulnerability to, the dangers associated with climate change.

The purpose of education is therefore to develop competent and creative individuals who would be useful to society; individuals who would contribute to the physical, intellectual and aesthetic development of the nation; individuals who would be aware of their social, economic and cultural environment, and would with self-confidence, make the necessary adjustments to meet a constantly changing environment.

The Sustainable Development Goal (SDG) 4 calls on governments to ensure inclusive and equitable quality education and promote lifelong learning opportunities for all. Target 4.1 of SDG4 stressed the need for government to ensure that all girls and boys complete free equitable and quality primary and secondary education leading to relevant and effective learning outcomes; and target 4.3 affirmed that by 2030 all men and women should have equal access to affordable and quality technical, vocational and tertiary including University education (UNESCO, 2016).

Education also makes it possible for people to be responsible and be informed citizens who participate in politics and society. It provides people with the knowledge and awareness needed to promote tolerance and understanding among people, in order to build a peaceful, harmonious and stable society where all men and women will live as brothers and sisters made in the image and likeness of God, our creator.

\subsection{Quality Education}

The International Organization for Standardization(ISO: 8402-1986) defined quality as follows: The totality of features and characteristics of a product or service that bear its ability to satisfy stated or implied needs. Goal 4 of the SDGs was a unique goal focused purely on quality education, ensuring inclusive and equitable quality education and the promotion of lifelong learning.

Quality in the context of education is a complex concept. Because of its complexity, many terms such as 'efficiency', 'effectiveness', and 'equity' are used as synonyms of it. There is a general consensus with regards quality education which includes:

- Learners who are healthy, well-nourished and ready to participate and learn, and be supported in learning by their families and communities;

- Environments that are healthy, safe, protective and gender-sensitive, that provide adequate resources and facilities;

- Content that is reflected in relevant curricula and materials for the acquisition of basic skills, especially in the areas of literacy, numeracy and life skills; and knowledge in such areas as gender, health, nutrition, HIV/AIDS prevention and peace;

- Processes through which trained and qualified teachers use child-centered teaching approaches in well-managed classrooms and schools and skillful assessment to facilitate and evaluate learning and reduce disparities;

- Outcomes that encompass knowledge, skills and attitudes, that are linked to national goals for education and positive participation in society. (UNICEF, 2000)

Sierra Leone's higher education system has been negatively affected by poor funding, limited staff training opportunities, ailing research infrastructure and the lack of effective quality management system. These have consequently led teachers at the higher education level not to align course content with the needs of the job market, the aspirations of the growing number of students and the educational goals of the country.

The enrolment of students in schools and colleges is not enough to ensure quality; quality teaching and learning materials must be made available in a well-structured learning environment dedicated to achieving quality learning outcomes. 
According to the World Bank (2007: p.), learning in many schools in Sierra Leone is limited and therefore learning outcomes are equally limited in scope which need to be improved. Teacher motivation is critical in the provision of quality education. Only about 30 percent of primary school teachers are satisfied with their jobs. The vast majority are dissatisfied. This is because of so many factors which include late payment of salaries, poor working and living conditions, lack of continuous in-service training opportunities etc. The same document pointed out the disturbing poor learning conditions and outcomes in the Technical Vocational Education Training (TVET) and tertiary education; outdated curricular that are of low relevance to the labour market.

Quality education focuses on the whole learner; the social, physical, mental and cognitive development of each student regardless of gender, race, ethnicity, geographic location of socioeconomic status. It is about ensuring student access to quality teachers; providing quality teaching and learning materials; providing continuous professional development and the establishment of safe and supportive quality learning environments. It is not simply about content delivery but a system designed to help all students reach their full potentials and operate in society as productive citizens. It prepares students for life and not just for examinations.

The decline of the quality of education and the relevance of the curricular to the job market, warranted the establishment of the SPHEIR project in 2017 for "Assuring Quality Higher Education in Sierra Leone (AQHEd-SL)", which brought higher educational institutions across the country together to enhance the quality of higher education service delivery, leading to improved management and implementation of outcome based education and the establishment of a National Qualifications Framework (NQF). The aim of the project was to support the implementation of outcome-based education through strategic curricula realignment and staff capacity building; also, to bring about a student-centered learning focus within higher educational system across the country, leading to a more responsive and capable national workforce.

\subsection{Teacher Outcomes}

Teacher outcomes specify what teachers need to know and do in order to deliver on the promise of an effective, equitable education for every student. The teacher outcomes included: knowledge, skills and dispositions related to content knowledge; pedagogical knowledge; assessment; understanding how student learn; understanding how students' cognitive, social, emotional, and physical development influence their learning; engaging students with diverse cultures, gender and socioeconomic conditions; creating learner-friendly learning environments; professional growth and development.

Student learning outcomes could be defined as the equitable expectations of students to achieve at high levels and hold teachers responsible for implementing appropriate strategies to support student learning. Learning for educators who focus on student learning outcomes has a positive effect on changing education practice and increase student achievement. Using student learning outcomes as its outcomes, teacher professional learning can model and engage educators in practices they are expected to implement within their classrooms.

Cedefop (2017: p.26) stated that:

The learning outcomes approach helps to orient teaching, to select methods and to support the learning process. Learning outcomes, through their focus on levels of, and requirements to, learning are crucial for promoting a more systematic reflection on assessment criteria and methods and how these interact with and support the learning process. Learning outcomes approach supports assessment by clarifying the criteria for success/failure and performance. While most frequently linked to summative assessments, learning outcomes can help with formative assessment throughout the learning process.

\subsection{Concept of Learning Outcomes}

Learning outcomes are statements of the knowledge, skills and abilities individual students should possess and can demonstrate upon completion of a learning experience or sequence of learning experiences. It is what the student is able to do, know about and value at the completion of a course of study. It states both the substance of learning and how its attainment is to be demonstrated. 
Cedefop (2017: p.26) also affirmed that:

For learning outcomes statements to make any difference to learners, they must be visible not only in (written) qualification standards and programme description. Their visibility in practice, throughout the teaching and learning process as well in assessment arrangements, is of critical importance and decides whether or not they add value to the individual learner.

Learning outcomes therefore provide a common language allowing different stakeholders in education and training, as well as the labour market and society at large, to clarify skills needs and to respond to these in a relevant way. If used systematically, this allows for systematic review of the quality and relevance of education and training, focusing on the relationship between intended and actually achieved learning outcomes. The definition of learning outcomes requires systematic reflection on the use of labour market intelligence and how this will be balanced with the needs of the education and training system and of teachers, to support education, training and learning.

\section{Statement of The Problem}

The quality and extent of student achievement are determined primarily by teacher competence, sensitivity to students' individual learning processes, and teacher motivation. The importance of quality teaching and learning outcomes in teacher education cannot be overemphasized, as it contributes to the overall capacity development of the individual for effective and efficient service delivery of the teaching in schools.

UNESCO's Sierra Leone Education Country Status Report (2013:p.123), affirmed that the ultimate negative impact on the quality of teacher education in the country included:

I. Courses are theoretical, lacking teaching practice, pedagogical skills components, field trips and laboratories;

II. Programmes (Curricula) are at risk of becoming outdated due to lack of regular review;

III. Teaching methods are inadequate, essentially lecture-based, and exams test mainly cognitive skills and memory; and

IV. Most students following TC or HTC Primary training are among the poorer WASSCE performers, which puts the starting level of teachers' competencies at a low level.

The study, therefore, seeks to examine the 'factors affecting quality teaching and learning outcomes in Teacher Education' in Sierra Leone.

\section{The Purpose of The Study}

The purpose of the study was to examine the factors affecting quality teaching and learning outcomes in teacher education in Sierra Leone.

\section{Research Questions}

I. What are past and continuing students' perspectives on the quality of education received?

II. What are the lecturers' perspectives on factors that affect students' academic performance in teacher education?

III. What are the challenges lecturers and administrators encounter in the provision of quality education?

IV. In what ways may the teaching and learning outcomes in teacher education be improved?

\section{THe Significance OF THE STUdy}

The findings of the study would help suggest ways of improving on practice, add to existing knowledge and to inform educational policy debate and decision-making processes with respect to providing the required educational resources needed to improve the quality of education in the country. It could be useful to the Ministry of Technical and Higher Education (MTHE), the Ministry of Basic and Secondary Education (MBSE), Non-Governmental Organizations (NGOs,), and teacher training institutions regarding how best they could address problems related to quality teaching and learning processes. On the other hand, the research findings might provide lecturers with vital 
information for use to present a case for the need of continuous professional development in content knowledge, pedagogy, review of curricula and other professional skills for quality delivery service for improved teaching and learning outcomes. The findings of the study might also contribute to the already existing body of knowledge and literature in the area of quality education and improve on practice in Sierra Leone and elsewhere, especially in the sub-region.

\section{LiMitATIONS OF THE STUDY}

The findings of the study were not generalized to reflect the situation in other tertiary teacher education institutions in the country. The study only covered 2 teacher education institutions out of a number of 7 in the country due to logistical constraints encountered by the researcher. Another limitation encountered by the researcher was time factor. Also, in some cases participants refused to speak against their institutions.

\section{ETHICAL CONSIDERATION}

Ethical considerations are vital in the provision of a pleasant atmosphere required for participants to answer questions with open minds. The aim of the research study was clearly explained to the participants before administering the questionnaires and conducting interviews. The researcher assured respondents of maximum confidentiality in their engagement in the study process. Respondents in turn fully consented to participate in the study.

\section{REVIEW OF LITERATURE}

The 1991 Constitution of Sierra Leone requires the Government to direct its policy towards ensuring that there are equal rights and adequate educational opportunities for all citizens at all levels by:

I. Ensuring that every citizen is given the opportunity to be educated to the best of his/her ability, aptitude and inclination by providing educational facilities at all levels and aspects of education such as primary, secondary, vocational, technical, college and university;

II. Safeguarding the rights of vulnerable groups, such as children, women and the disabled in secured educational facilities; and

III. Providing the necessary structures, finance and supportive facilities for education as and when practicable. (GoSL,1991: p.9).

The quality and extent of students' achievements are determined primarily by teacher competence, sensitivity and teacher motivation. The importance of quality teaching and learning processes in teacher education cannot be overemphasized, as they contribute to the overall capacity development for effective and efficient service delivery of the would-be teachers in the teaching profession in the country. Therefore, quality education is significant for personal and economic growth, as it powers nations to reduce poverty; improve the lives of individuals and groups and transform society or a nation.

The quality of teachers is determined by who are attracted to enter the profession and how they are trained. The society expects teachers to be sufficiently knowledgeable in the subject-matter, pedagogy and other soft skills- Communication, inter-personal relationship, and professionalism or work ethics. Thus, the need to enhance teacher education programmes for the training of quality teachers for active participation in the teaching and learning processes in schools.

\subsection{Teacher Education}

Teacher Education is concerned with the process of producing teachers with the knowledge, attitudes, behaviours, values and professional skills and techniques necessary to teach and perform other duties effectively in a classroom or learning environment. It is thus aimed at producing qualified teachers for gainful employment in the teaching field. Kumar (2016:p.1217) affirmed that teacher education is a process for the development of proficiency and competence of teachers which in turn would enable and empower them for meeting the requirements and challenges of the profession in present times.

The African Union (AU) Conference stressed the need for governments to ensure gender sensitivity in learning environments and in teaching and learning materials for quality teaching and learning outcomes. (African Union; 2006-2015, p.5). 
Teacher Education serves to equip the student-teachers with the conceptual and theoretical framework, within which they can acquire an understanding of the intricacies of the profession. It is aimed at the formation of positive attitude among the individuals so that they could be able to cope up with the challenges and problems in a positive manner. The individual students get empowered with the skills and abilities so they are able to perform all relevant tasks and functions in an operative and efficient manner.

\subsection{Quality Education}

Quality, is defined as'the standard of how good something is measured against other similar things; an improvement in product quality' (Compact Oxford English Dictionary (2005: p.833). It is about how good or bad something is; thus, it is used for every commodity. For example, quality shoes, cars and so on. When a woman is selling mobile phones in a market sees a potential customer approaching her shed, she will not waste time to make use of 'quality' to draw potential customer nearer for the purchase of her mobile phone. Thus, she will say 'buy high quality mobile phone'. This means that any commodity can either be of high or low quality. Similarly, we have low quality and high-quality education.

The former UN Secretary General, Ban Ki-moon, in 2012 set the SDG process in motion by declaring that every child must be in school, and the quality of those schools (educational institutions) must improve so that students are prepared to be productive citizens, ready to lead the future. Education is not simply to be perceived as a content delivery system; rather, it is a system designed to help all boys and girls, men and women reach their full potential and operate in society as full and productive citizens.

The Association for Supervision and Curriculum Development (ASCD) and Education International (EI) (2015) based in Brussels-Belgium, released a statement in support of the SDGs and the pursuit of quality education for all. In the statement, they defined quality education as:

One that focuses on the whole child - social, emotional, mental, physical, and cognitive development of each student regardless of gender, race, ethnicity, socioeconomic status, or geographic location. It prepares the child for life, not just for testing (ASCD \& EI, 2015).

According to the statement, quality education is supported by three key pillars, namely: access to quality teachers; provision of quality learning tools and professional development; and the establishment of safe and supportive quality learning environment (ASCD \& EI, 2015).

The Gbamanja Commission (2010), also highlighted similar key factors or reasons for the poorquality performance in the Sierra Leone educational system. These included the following: Extralarge class sizes which made teaching and learning an exercise in futility, inadequate teaching and learning materials, and inadequate coverage of the syllabus (p.28-34).

According to the Education for All (EFA): Global Monitoring Report (2005: p.17), two principles characterize most attempts to define quality in education. The first identified learner's cognitive development as the major explicit objective of all education systems. The second emphasized education's role in promoting values and attitudes of responsible citizenship and nurturing creative and emotional development.

Quality determines how much and how well children learn and the extent to which their education translates into a range of personal, social and developmental benefits. Goal 6 of the Dakar Framework for Action (2000), emphasizes the need of a stimulating pedagogy. It is the teaching and learning process that brings the curriculum to life, which determines what happens in the classroom and subsequently, the quality of the learning outcomes.

Quality teaching is doing whatever it takes, ethically and responsibly, to advocate and ensure that students learn and they leave the classroom with a passion for learning. It is about the enthusiasm a teacher has about teaching; creating a good learning atmosphere; uses methods and techniques that are effective in helping students to learn; giving positive feedback to students; showing genuine interest in promoting students' academic progress, and moreover communicating the content of the subject matter well with the class. (Macquarie University website, 2019). 
Teachers are required to focus on performing their duties in a manner that would not only lead to the acquisition of academic knowledge among the students, but also the development of morality and ethics among them. The students enroll in educational institutions, not just to hone their academic skills and abilities, but also to acquire the knowledge of principles, standards, values and norms, so that they can contribute effectually towards promoting well-being of the community and nation. For this purpose, it is vital for the teachers to put into practice modern and innovative strategies and methods that would lead to overall growth and development of the students.

Quality Education is supported by three key pillars, namely: Ensuring access to quality teachers, providing use of quality learning tools and professional development, and the establishment of safe and supportive quality learning environments.

\subsection{Quality Teachers}

The educational leadership Policy Standards: Interstate School Leadership Licensure Consortium (Smith, 2009: p.221); standard 2 stated that:

An education leader promotes the success of every student by advocating, nurturing and sustaining a school culture and instructional programme conducive to student learning and staff professional growth.

Each child, in each school, in each community deserves to be to be educated by a qualified teacher. The 2030 SDGs rightly recognized the centrality of qualified teachers to the attainment of quality education. Students who are taught by well-trained, professionally qualified, motivated, and supported teachers perform better and remain in school and the education system longer. Nations should endeavor to provide nothing less than all children being taught by qualified teachers.

According to the World Bank (2007: p.5-7), learning in many schools in Sierra Leone is minimal and therefore learning outcomes are not fully achieved. There is therefore need for improvement. Teacher motivation is critical in the provision of quality education. Only about 3.6 percent of lecturers are satisfied with their jobs. The vast majority of the other lecturers are dissatisfied. This could be as a result of late payment of salaries, poor working and living conditions and lack of continuous inservice training opportunities, etc. The same document identified the disturbing poor learning conditions and outcomes in the TVET and tertiary education; outdated curricular and its low relevance to the labour market.

The researcher, totally agreed with the World Bank's statement on the poor teaching and minimal learning outcomes in the country's educational system. These minimal learning outcomes were as a result of many factors such as: Inadequate funding, poor teacher motivation and lack of other educational resources. If these issues are well addressed, there would be improved teaching and learning outcomes in the educational system.

The Education Sector Plan (2018-2020: p.75) agreed that many teachers still lack the relevant qualifications for the levels in which they teach. Quality teachers should have the requisite subject matter knowledge, pedagogical skills and attitudes for effective teaching; a strong understanding of child development; effective communication skills; a strong sense of ethics and a capacity for renewal and continued learning. In-service training should include training in all of these and other critical areas. Teacher professional development training is key for improved practice. It is therefore, vital that teachers and educators be given opportunities, in a form of grants or scholarships.

The teacher's care extends to every aspect of the learning environment, including curriculum, instruction, assessment, and society. If students are aware that teachers care, they will be more willing to make an effort to please the teacher. As a teacher, one needs to lead your students by example. Displaying a caring attitude toward each student will encourage them to treat each other with the same attitude. Dealing with conflict in a caring and understanding manner will have the same effect. Teachers need to encourage all learners to treat each other with respect and care, because this promotes a positive learning environment and can improve collaboration among students.

The teacher's role is fundamentally the primary contributor to the attainment of conducive learning climate and culture. Your interaction with the students, disciplinary measures, mannerisms, support, encouragement, cooperation, and focus on individual students all contribute to an atmosphere conducive to learning. 
Although they are complex and multifaceted, classrooms with a climate and culture conducive to learning share similar characteristics. The teacher should be caring and supportive to the students' learning processes. The lessons should be well organized, progress smoothly, and free from interruptions. The content should be challenging without being frustrating, and activities relevant and must interest students. Open, warm relationships among students are encouraged, and cooperation and respect are expected. Stress and anxiety levels are low, and there is limited conflict.

\subsection{Quality Teaching and Learning Tools/ Materials}

Quality teaching requires quality tools and ongoing professional development throughout the career of the educator. The phrase 'quality tools' refers to the use of teaching and learning materials and resources, as well as the training in effective pedagogy that accompanies them. A flexible curriculum that is able to adjust and suit the levels and interests of each learner and designed through an inclusive process that guarantees teachers' participation is highly desirable. Likewise, educators want appropriate, state-of-the-art tools to assess student learning in order to inform teaching strategies. Formative assessment that is diagnostic and developmental, focuses on developing the whole child, spans the whole school, and is supported by conditions both in and out of school can be used to support teachers to improve learning.

According to the World Bank (2007: p.1), financial resources play a key role in delivering quality education services. They stressed that the education sector requires much more in terms of (finance) if the system is to be expanded, quality improvements made, and national and international goals met.

The Education Sector Plan (2018-2020: p.59) affirmed that:

Poverty is seen as a major reason why children do not participate well in schools. Many students lack basic learning materials such as textbooks, exercise books. This obviously hinders a student's ability to learn effectively.

Often the learner's attendance depends on the income of the family. Cost is a factor that contributes to students' failure to participate fully in college or school. Children or young boys and girls would rather go to the streets to sell so that they can supplement their family's income rather than attend college or school. This trend has contributed negatively to academic performance of these students who find themselves in such a bad situation, because they miss college or school most of the time, arrive late for classes and have less time to do assignments and other academic work.

\subsection{Quality Teaching \& Learning Environments}

The educational leadership Policy Standards: ISLLC 2008; Standard 3 stated that:

An education leader promotes the success of every student by ensuring management of Organization operation and resources for a safe, efficient and effective learning environment (p.37).

For improved teaching and learning outcomes in teacher education in the country, all decisions in teacher education institutions should have the best interest of students in mind. The principal's behaviour, attitude, actions, and decisions have an adverse effect on the success of the college. Colleges should have enough physical space and adequate number of teachers and classroom to ensure class size. The college building and surroundings should be clean, safe from hazards and in good repair.

Quality teaching and learning processes, even when supported by essential resources and tools, can only be effective if conducted within environments that are safe, supportive, and conducive for effective teaching and learning. The SDG goal 4 recognizes that quality education cannot take place without safe and inclusive learning environments.

The Glossary of Education Reform (2013: p.1), in defining learning environment stated that:

Learning environment refers to the diverse physical locations, contexts, and cultures in which students learn. It is the culture of a school or class; its presiding ethos and characteristics, including how individuals interact with and treat one another; as well as the ways in which teachers may organize and educational setting to facilitate learning. 
For better academic performance in teacher education, the learning environment, therefore has both direct and indirect influence on student learning including their involvement in what is being taught, their motivation to learn, their sense of well-being, belonging and personal safety. Quality education, therefore, cannot take place without safe and inclusive learning environments.

In establishing the climate for teaching and learning the Gbamanja Commission (2010: p.26) agreed that:

The school environment consists of the physical environment i.e., the physical conditions and facilities for learning. Besides there are the social conditions which are developed and sustained by the nature of the interaction between the pupils and teachers.

Improved teaching and learning outcomes, classroom interactions and classroom management, even though it may be supported by essential resources and materials, can only be effective and productive if they are conducted within environments that are safe, conducive, and responsive to the various needs of the learner. Thus, the institutional physical structures and facilities form part of the learning environment. According to Senge (as cited in Armstrong, 2012: p.285), quality learning environment is:

...where the learners continually expand their capacity to create the result they truly desire, where new and expansive patterns of thinking are natured, where collective aspiration is set free, and where the learners are continually learning how to learn together.

Teaching and learning processes could be more improved if the institution and its physical structures or facilities were more supportive of creativity and innovation. It is a belief that in creating a learnercentered physical environment requires the development and implementation of a strategic plan for positive change.

Teaching and learning outcomes can only be more improved in an institution if it involves making that institution and its physical environment more supportive of creativity and innovation. The physical environment can have an impact on creativity; it encourages people to see new connections and to think more broadly; and that it has a major impact on the depth of communication and knowledge sharing (Harvard, 2003: pp. 110-111).

Creating this physical environment that puts students at ease and makes them feel relaxed and safe, will get the creative juices in them flowing. A college physical environment that is supportive of critical thinking, should be free of high level of noise, heat temperature and distractions in any form. It is a belief that moderate noise level is the sweet spot for creativity and critical thinking, thus an ambient noise gets creativity out, and it does not put students off like high levels of noise do. When a classroom or library is in an ambience state, fully equipped with educational resources, and fully air conditioned, will make students to concentrate and engage in critical thinking while doing their assignments and research studies which at the end improves academic performance or learning outcomes.

Institutional change can only be effective when an institution undergoes the process of strategic change to achieve and maintain a competitive advantage. Creating a caring, learner-centered physical environment takes lots of planning and decision-making processes. This therefore calls for a review of institutional strategic plans, and the implementation processes for improved academic performance.

For one to change people's behavior and performance, the learning environment (physical space) has to be conducive. Therefore, institutional physical structure provides support for both staff and students in the teaching and learning process. It ensures safety and security for both staff and students, motivates the learner, enhance learning outcomes and reduces behaviour problems. It also informs and engages the learner in critical thinking and reflections on issues raised in and outside the classroom. The physical classroom environment therefore affects the morale and willingness to engage in constructivism or critical thinking, which could lead better academic performance. This however, enhances the student's sense of belonging, being loved and cared for during teaching and learning processes. The physical environment helps build relationship among learners and among learners and lecturers. Therefore, the physical structure or environment of the institution should match the teacher's objectives both in terms of human interaction and the instructional approach, which enhances active collaboration and interaction among learners and teachers. 
Smith (2003: p.311) agreed that a collaborative, stimulating and challenging environment can significantly enhance performance and growth for every individual, whether it be an infant learning to speak; a worker on the job or a student in the classroom. The physical structure or classroom promotes a sense of well-being, keeps the mind focused and limit distractions. Therefore, a welldesigned or re-designed physical learning environment enhances high performance and quality teaching and learning outcomes.

Educational institutions have the responsibility to create space that reflects the learning goals of the workplace, the personality, interest, and age of the students who learn there and also to create space that is comfortable and productive for all. Any poor physical environment has adverse effect on the effectiveness and efficiency of staff and students for quality teaching and learning outcomes. These included the following: Lack of creativity and innovation in teaching and learning, lack of lecturers and students' motivation, non-collaborative and interactive practices, lack of a sense of belonging, being cared for and not safe for a healthy relationship, poor performance in teaching and learning outcomes and inactive participation in sustainable economic and national development.

He also highlighted some principles for establishing quality learning environment, which included the following: Establishing high degree of trust and respect, making sure both learners and teachers are committed to the learner's success, getting students involve very early in the process, challenging students on critical thinking, setting clear and high expectations, encouraging risk-taking, seeking and giving feedback regularly, and creating a collaborative learning space. (Ibid. p.311).

In conclusion, the literature presented so far stands reasonably clear that the accomplishment of what could be referred to as quality education as defined in this study, is quite a daunting task. It requires the wellbeing of the learner, a physical conducive learning environment of the learner, educational resources, and the content of the learning, the learning process, and the learning outcomes in consonance with the national goals of the country. Quality teaching and learning outcomes could only be improved if the many challenges were addressed.

\section{RESEARCH METHODOLOGY}

\subsection{Research Design}

The study was conducted using the mixed method approach of both quantitative and qualitative techniques in order to achieve accuracy and efficiency in the data collection. Qualitative method is a form of research that involves description, while quantitative is a systematic process for generating information using numbers. In addition, the study used observation method as another source of data collection.

\subsection{Study Area}

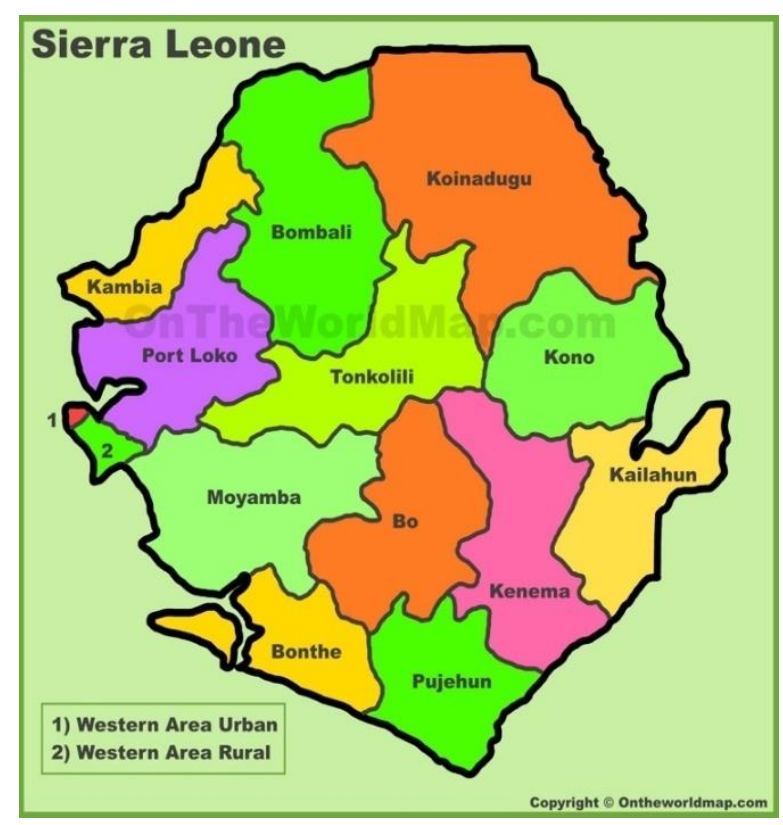

Source: Ontheworldmap.com. 
Sierra Leone is a relatively small country situated on the west coast of Africa. It is bounded on the west and south-west by the Atlantic Ocean, on the north, north-west and northeast by the Republic of Guinea, and on the east and southeast by the Republic of Liberia. It has a total population of about 7,092,112 of which 3,490,978 are male and 3,601,135 are female (Statistics SL 2015 Population Census). The country gained its political independence from Great Britain in April 1961.

After independence, the country maintained the educational system inherited from the British system of education. English was declared the official language of the country; and is the official language of instruction in schools, colleges and universities, and of the media and administration. The country was fondly called the Athens of West Africa as it had one of the first universities in Africa. Although the standards in schools and colleges were high, especially up to a decade after independence, it became clear that the curricula at the various levels of the educational structure did not meet the needs of the country at that time.

Sierra Leone's system of education, '6-3-3-4' i.e., six years of primary schooling, three years of 'Junior Secondary School', three years of 'Senior Secondary School', and four years of 'University or Tertiary Education', was introduced in 1993, and enacted into law through the 2004 Education Act, (GoSL, 2004).

The scope of the study was limited to the factors affecting quality teaching and learning outcomes in Teacher Education in Sierra Leone. The study was limited to two (2) teacher training institutions out of seven (7) teacher education institutions in the country.

\subsection{Population and Sample}

Population means a group from which the study sample was drawn. The targeted population of the study included the following: Administrators of both institutions in the study, lecturers, past students, continuing students of both institutions of the study, officials of the Ministries of Education, Teaching Service Commission (TSC) and the Tertiary Education Commission (TEC). The study sample comprised 100 participants drawn from the targeted population as indicated in the table below.

Table1. Key Participants

\begin{tabular}{|l|l|l|l|l|l|}
\hline & Lecturers & Administrators & Alumni & $\begin{array}{l}\text { TEC, TSC, } \\
\text { Ministry of } \\
\text { Education }\end{array}$ & $\begin{array}{l}\text { Continuing } \\
\text { Students }\end{array}$ \\
\hline Total & 30 & 14 & 10 & 06 & 40 \\
\hline
\end{tabular}

The researcher purposively selected administrators of the 2 institutions in the study; officials of the Ministries of Education, TEC and TSC, considering their active involvement in teacher education. The researcher also used the same purposive method at random to select past students of both institutions in the study.

\subsection{Research Instrument}

The study involved questionnaires and interview schedule guide with the aim to address the study objectives. Before the actual study, a pilot administration of the questionnaires and interview schedule guides was conducted at Freetown Teachers College. The purpose of the pilot study was to enhance reliability and content validity of the instruments by refining vague statements in the instruments or remove them completely.

The modified questionnaires were checked to determine whether they were in conformity with the objectives of the study. The questionnaires were administered to participants on spot and by appointment where necessary.

\subsection{Data Collection Procedures}

The researcher administered the research questionnaires, conducted interviews, focused group discussions, and carried personal observations. Aboutninety (90) percent respondents participated in the study.

\subsection{Data Analysis}

Using the Statistical Package for the Social Sciences (SPSS) version 12.0 the responses from the collected data were statistically analyzed and presented into frequencies with the corresponding percentages and charts to illustrate the results of the study. Data from interviews and some from the 
questionnaires were qualitatively analyzed, by picking out words and expressions frequently used by the interviewees and organizing them into categories or themes under-utilization of the package.

\section{FINDINGS}

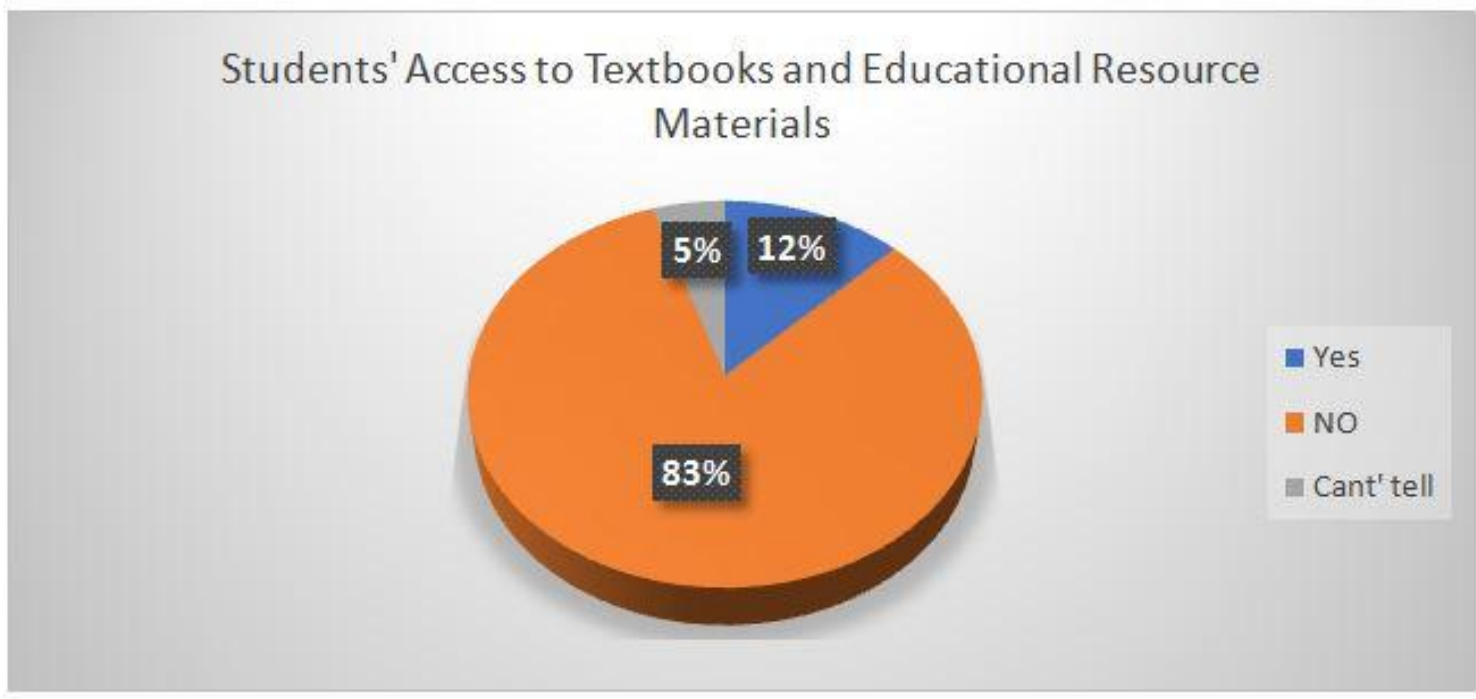

Chart1. Students' Access to textbooks and educational resource materials

In response to whether the respondents had access to textbooks and other educational resources relating to their courses, about83 percent of the respondents had no access to educational materials, while about 12 percent of them had materials. During the focus group discussions an alumni had this to say:

'Me way ar be dae do me study na college (when I was doing my studies at college), we had no textbooks to consult or copy from. One day I had an assignment in Educational Administration, I went to the library to look for a book on the subject-matter, but to no avail'

Non-availability of essential course textbooks in all course areas was a cause for concern for students' learning achievements and performance. It is a clear indication that majority of the students at teacher training institutions did not have access to textbooks and other related educational resources for their academic work.

\section{Rating of College library by both staff and students}

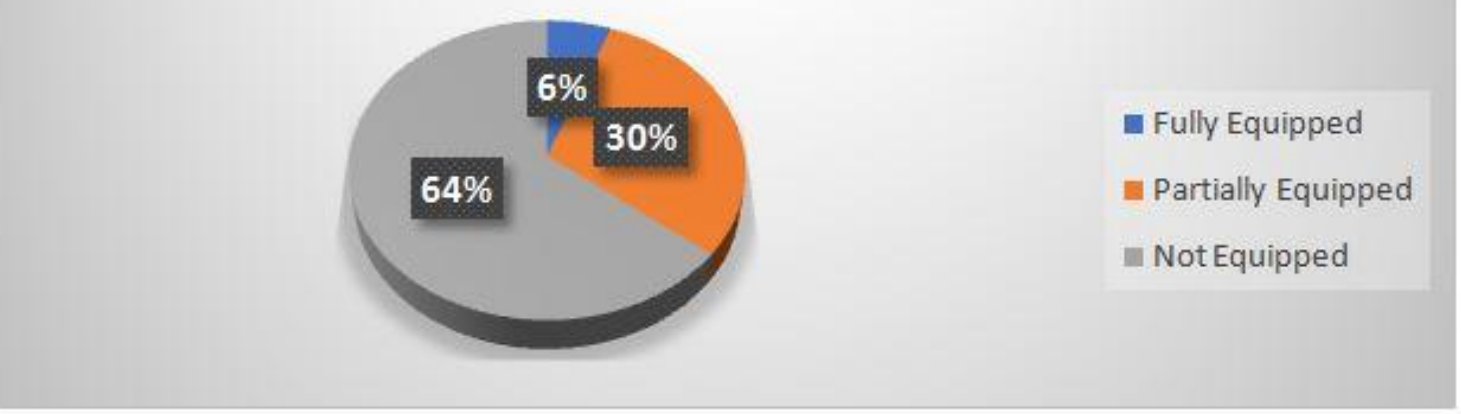

Chart2. Rating of College library by both staff and students

Regarding the question as to how well their college library was equipped about 64 percent of the respondents reported that the library was not equipped, while 30 percent of them responded that library was partially equipped. It is obvious that Teacher education institutions should endeavor to fully equip their libraries with updated and current educational material for staff and students' use in their teaching and learning process. 


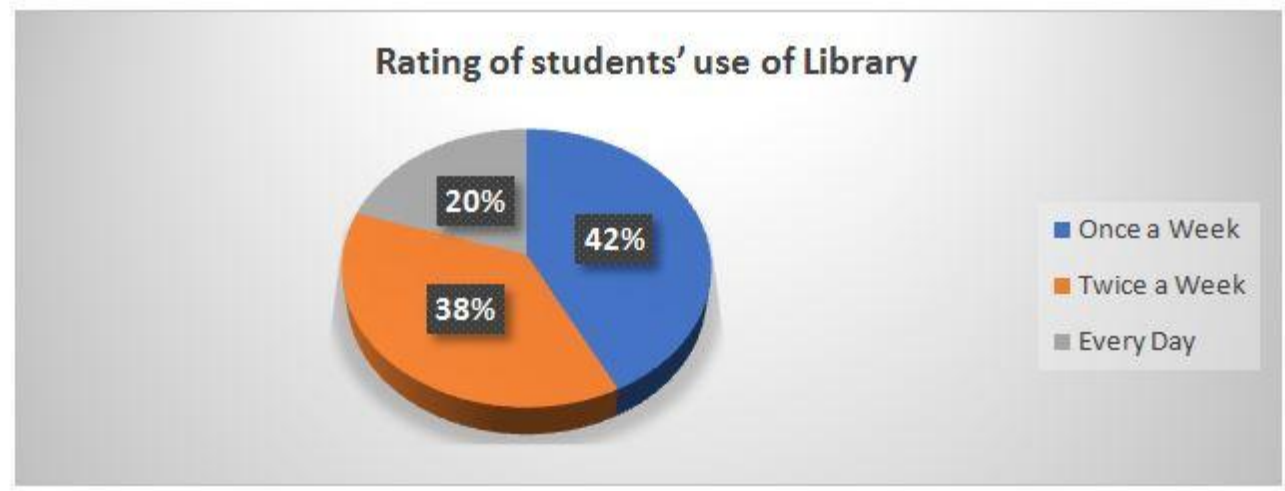

Chart3. Rating of students' use of library

In response to how often the respondents used the library, about 42 percent of them indicated that they used the library only once per week, while 38 percent of them used the library twice a week. Only20 percent indicated that they used it every day. This was an indication that the majority of students did not use the library every day for their academic work.

\subsection{Rating of Science Laboratory}

The respondents were asked to indicate how well their science laboratory was equipped. The result was disappointingly negative as only 15 percent of the respondents reported that their laboratories were only partially equipped. In fact the remaining 85 percent of the respondents reported that they did not have a science laboratory. Speaking on the issue of science laboratory during the focus group discussions, it came out vividly that teacher training institutions in the country did not have science laboratories. This was what a member of the focus group member said:

'Science laboratories in schools and colleges? Forget about it. You can't see any functional one. It is non-existent. Doing sciences is a daunting and challenging task without alab. We were only taught theories on the chalk board with no hand-on practice. That is why science is dead in schools and colleges.

This is an indication that the institutions should endeavor to provide fully equipped laboratories with the necessary apparatus and reagents in order to make science interesting and effective for students' academic work. It is very important that all colleges preparing science teachers to have well equipped laboratory.

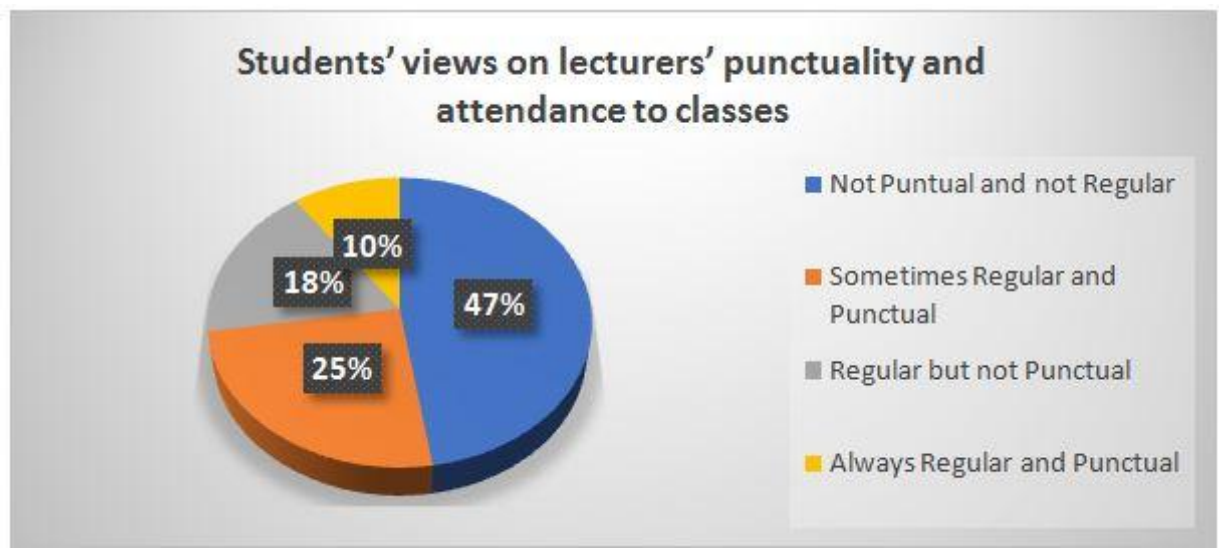

Chart4. Students' views on lecturers' punctuality and attendance to classes

When the respondents were asked to indicate their lecturers' attendance and punctuality for classes, the results showed that about 47 percent of the respondents indicated that their lecturers were not regular and punctual to their classes when they should. About 25 percent indicated that lecturers were sometimes regular and punctual, and 18 percent of them indicated lecturers were always regular and punctual. Only 10 percent of the respondents affirmed that the lecturers were regular but not punctual for their classes when they should. Discussing the issues of lecturers' regularity and punctuality for classes during the focus group meeting, members affirmed the same that lectures were not regular and punctual for classes. An alumni had this to say: 
You can't believe it sir, you see, when some of these lecturers don't go for lectures, the day they were available they will just rush through the lesson. Whether we the slower learners grasp the concepts of the topic or not, that is not their business. You know what? Some of us lag behind and this affected our academic performance, which is not good. This should not happen. Students also lag behind because they don't go for lectures, what do you expect? Poor performance and standards.

The results indicated that majority of the lecturers were not regular and punctual for their classes when they should.

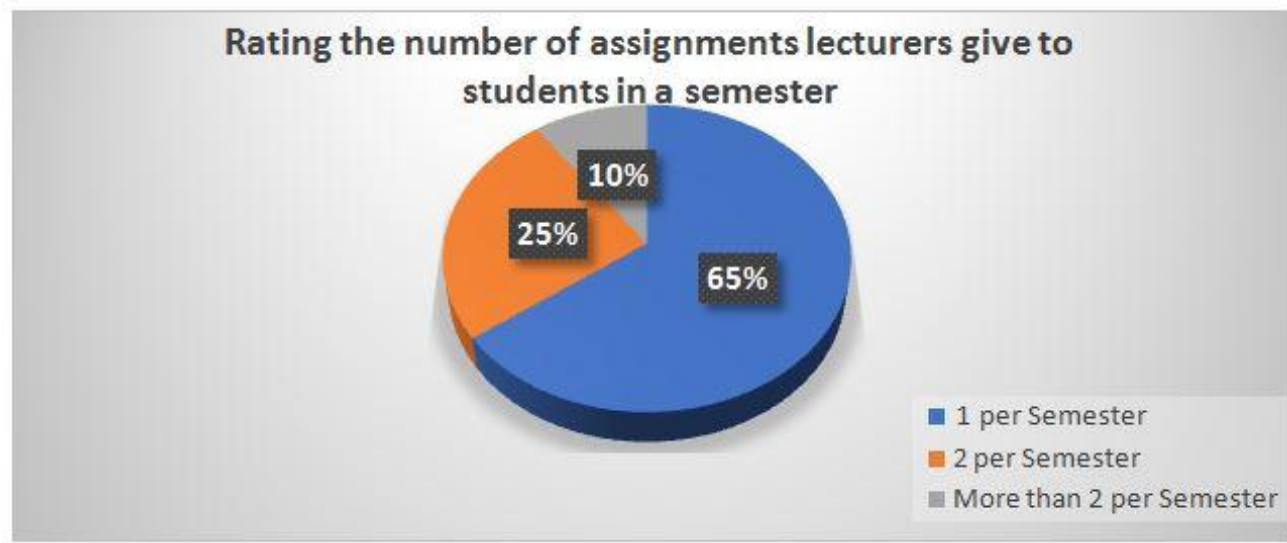

Chart5. Rating the number of assignments lecturers give to students in a semester

The results in chart 6 , showed that about 65 percent indicated that lecturers only gave 1 assignment to students during the semester, and 25 percent of them affirmed that only 2 assignments were given, while only 10 percent of them indicated that lecturers gave more assignments during the semester. The results, therefore, mean that the majority of lecturers did not regularly give assignments to their students during the semester. The non-giving of assignments regularly could handicap the lecturers from getting an insight into whether the students have grasped the pedagogical skills and content knowledge of the subject matter. In addition, this will affect the students' critical thinking, and eventually low academic performance.

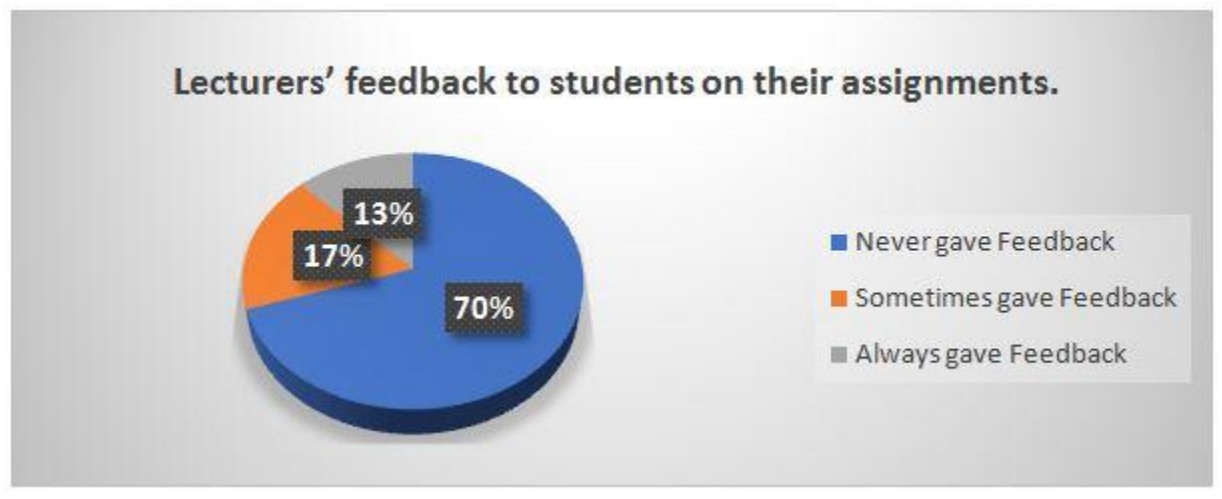

Chart6. Rating lecturers' feedback to students on their assignments

When the respondents were asked to indicate the frequency of lecturers giving feedbacks to students, about 70 percent of them indicated that the lecturers never gave feedback on assignments after marking their scripts, while only 13 percent of the respondents indicated that lecturers always gave them feedbacks on their performance. The result, therefore, could mean that the majority of the lecturers never gave feedback to students after marking their scripts. Furthermore, this could be demotivating to both studious and non-studious students which could lead to low academic performance.

\subsection{Rating Lecturers' Completion of Teaching Syllabi by Students}

The completion of the teaching syllabus has an effect on teaching outcomes and students' academic performance. Therefore, the researcher was interested in the completion of the subject-matter teaching syllabus. 
The results showed that about 54 percent of the respondents confirmed that lecturers never completed their teaching syllabi, while only 14 percent of them reported that lecturers always completed their teaching syllabi. One respondent during the focus group discussion had this to say:

'Dae lecturer dem nor dae complete the course syllabus (the lecturers do not complete the course syllabus). Instead, they force we for buy their pamphlets and other photo copy material from where they draw their questions for exams. Failure to comply is failure to pass. So at the end of the day, we jus get for buy am en memorize dae notes for exams. This nor good at all en nar bad service to the students way don pay college fee' (we just have to buy it and memorize the notes for exams. This is not good at all and it is bad service to the students who have paid college fees).

This is an indication that majority of the lecturers never completed their subject-matter teaching syllabus. The non-completion of the teaching syllabus was a show of lack of commitment to duty and service to the students, which could have a ripple effect on students' learning outcomes.

\subsection{Students' Attendance and Punctuality for Classes Based on the Lecturers' Views}

The researcher also sought the opinion of the respondents on student's punctuality and attendance for classes when they should, which could have some ripple effects on their academic performance.

The results indicated that about 52 percent of the respondents confirmed that students were not regular and not punctual for classes when they should. Only about 18 percent of the respondents answered that students were always regular and punctual, and while about 30 percent of them stated that the students were regular but not punctual for classes when they should. The indication is that the majority of the students were irregular and not punctual for their classes. However, when compare with the results in chart 5 on lecturer's attendance and punctuality, one may not be sure of who was saying the truth as the percentages on 'not regular and not punctual' (47 percent in chart 5).

\subsection{Rating Students' Submission of Assignments}

The researcher also sought the opinion of the respondents on the submission of assignments by students for grading which could have some ripple effects academic performances.

The results indicated that about 46 percent of the respondents affirmed that the students never submitted their assignments for grading. About 18 percent respondents indicated that some seldomly submit assignments, while about 36 percent of them reported that the students submitted their assignments for grading. The indication is that the majority of the students never presented their assignment scripts for grading and therefore, poor learning achievement.

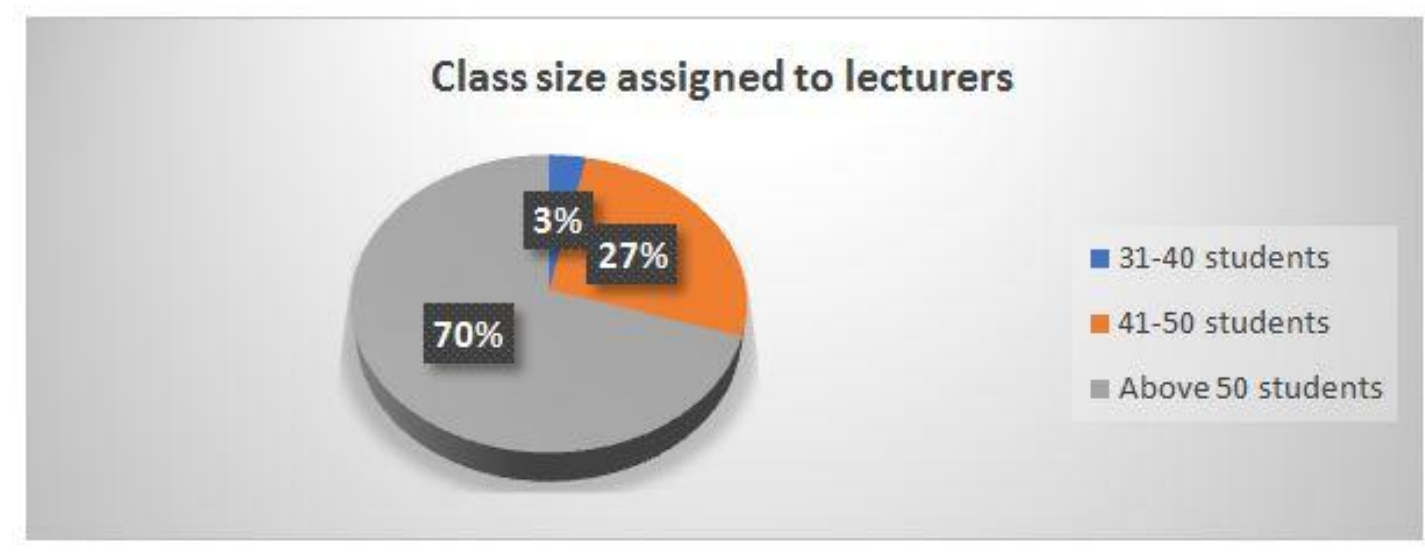

Chart7. Rating class size assigned to lecturers

The results in chart 8 above indicated that about 70 percent of the respondents indicated that the class size they taught was above 50 students. About 27 percent of them indicated 41-50 students, and only 3 percent of them stated that indicated 31-40 students. The indication was that the majority of the lecturers taught classes that were above 50 students.

The researcher also sought the opinion of respondents on the subject of job satisfaction which could demotivate staff from performing, and also affect students' learning outcomes. 


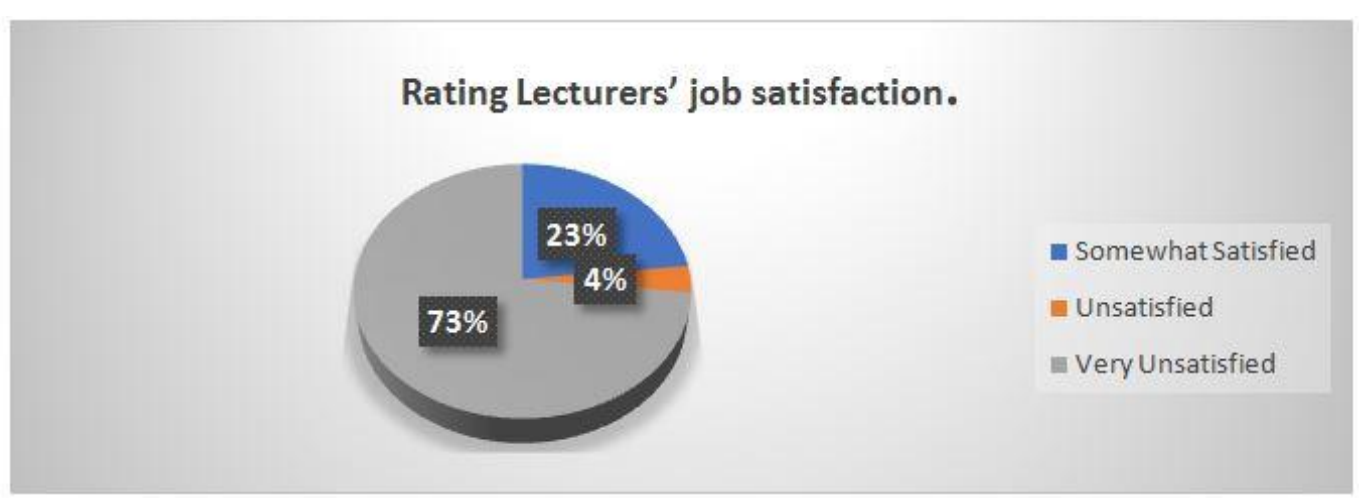

Chart8. Rating Lecturers' job satisfaction

From the results in chart 8 showed that, about 73 percent of the respondents indicated that they were very unsatisfied with their job. Only about 23 percent of them indicated that they were satisfied with their job. The results indicated that majority of the lecturers were very unsatisfied with their job. This could have a ripple effect on the performance of staff. For example, they would be more likely to call sick, even though they were healthy enough to work, or absenteeism and unpunctuality would become the order of the day, which could affect students' academic performances, due to lack of syllabus coverage of the subject-matter.

\subsection{Rating the Review of Teaching Curriculum Based on Lecturers' Views}

The researcher was interested in the subject of review of teaching curriculum which has some effects on teaching and students' learning outcomes.

The results indicated that about 82 percent of the respondents answered that the review of the teaching curriculum was reviewed 11 years ago. About 14 percent of the respondents stated that the review was done 10 years ago. Only about 4 percent of them reported that the teaching curriculum was done 5 years ago. The general impression was that the majority of the lecturers reported that the teaching curriculum was reviewed 11 years ago and therefore obsolete to achieve the desired goals of teaching and learning.

Curriculum review is a critical examination of academic programmes for the purpose of optimizing student learning experiences led collaboratively by academic staff who teach within the programme. The aim of it is to understand how well the curriculum supports and contributes to student learning experiences and how they can be enhanced for academic performances.

\subsection{Rating the Infrastructure}

The researcher was also interested on the subject of infrastructural facilities for teaching and learning processes. Classrooms, laboratories, libraries, offices and other educational recreational facilities are crucial elements of teaching and learning environment in any educational institutions which have some effects on teaching and students' learning outcomes.

In response to whether the teacher training institutions' infrastructures were adequate, the results indicated that about 79 percent of the respondents indicated that the infrastructure were very inadequate. Only about 21 percent of them reported that the infrastructure was somewhat adequate. This was a clear indication that the institutions' infrastructure was not adequate for effective teaching and learning outcomes.

\subsection{Rating of Funds Received from Government}

Adequate funding of education is key for quality teaching and learning outcomes. The researcher was interested to know whether the funds received from the government were adequate.

The results indicated that about 79 percent of the respondents reported that government funding to the colleges was very inadequate. However, only about 7 percent of them stated that funds received from government were somewhat adequate. The general indication was that the majority of the administrators confirmed that funds received from government were very inadequate.

Thus, inadequate funding has negative consequences on the teaching and learning processes. The nonprovisions of textbooks, recent educational journals, staffing and capacity building, motivation, and other educational resources which affects staff and students' academic performances hinges on the availability of funding. 


\subsection{Summary of Major Findings}

The results of the study highlighted various factors that affected the quality of teaching and learning processes and outcomes in teacher education institutions in Sierra Leone. The key results included the following:

Firstly, the inadequate funding of the teacher education institutions. Lack of adequate funding affects the provisions of the necessary infrastructures and educational resources needed for quality teaching and learning processes, which has a negative impact on teaching and students learning outcomes.

Secondly, the lack of adequate infrastructural facilities such as: Adequate and spacious classrooms for lecturer-students interaction and collaborative learning among students; lack of fully equipped library facilities for students' self-learning and discovery of new knowledge; non-existent of science laboratories for demonstration, experiments and students' practice; and recreational facilities for social interaction among students and staff. These challenges have negatively impacted teaching students' academic achievements.

Thirdly, the lack of staff and students' access to textbooks, recent professional journals and other educational resources for gainful acquisition of relevant and current content knowledge of the subject matter and other new discoveries. This factor has a negative impact on teaching and students' performances in their academic work.

Lastly, the frequent absence and lateness for classes by both lecturers and students undermine performance. In cases where lecturers are not frequent and not punctual, they rush with the delivery of the content knowledge of the syllabus, thus robbing the students especially the slower learner the opportunity to grasp the content knowledge and skills. For the students who are not regular and not punctual lag behind or miss out considerably, which negatively affects their performance.

\section{CONCLUSION}

Based on the findings of the study, the following conclusions were made. The factors which affected quality teaching and learning outcomes in Teacher Education included lack of enough textbooks and other educational resources, high lecturer-student ratio, lack of laboratories and lack of adequate library facilities.

The study also found that lack of staff professional development training, outdated curriculum, and lack of lecturers' motivation greatly affected the commitment and performance of the teaching staff, which eventually affected students' academic performances.

Finally it was suggested that to improve quality teaching and learning outcomes in teacher education, both the government and the college administrators should motivate the teaching staff by paying them well. They should also provide adequate teaching and learning resources, provide opportunities for staff professional development, ensure a conducive environment in colleges, and provide adequate physical facilities in the colleges.

\section{RECOMMENDATIONS}

Based on the results of the study, the following recommendations were made for improved teaching and students' academic achievements in teacher education.

\section{Administrators' Recommendations for the Attention of Government}

For improved teaching and students' academic performance, the following recommendations were made by the college administrators for the attention of the government. These recommendations included the following:

i. Respondents of the study recommended that Government should increase its budget allocations of the national budget to the Ministry of Technical and Higher Education for direct funding to the teacher education institutions for their infrastructural development programmes. Increased in funding will help the institutions to build more adequate classrooms in order to reduce class sizes for better teaching and learning processes and for improved academic performance.

ii. A recommendation was made by respondents of the study, that government funding should release funds on a timely on a basis in order to address the many and urgent needs of the institutions in enhancing quality teaching and learning outcomes.

iii. For improved learning outcomes or students' academic performance in the sciences, colleges must have fully equipped science laboratories to make science interesting and effective. The 
researcher is of the opinion that a performing teacher training college has to combine classroom teaching with laboratory experiments to ensure students grasp each and every scientific concept thoroughly. Therefore, it was the recommendation of the respondents that government should build a well-equipped science laboratory on each college campus without delay.

iv. Job satisfaction in any field of work depends a lot on how conducive the work environment is. The work itself, the pay and conditions of service, are only some of the factors which have an impact on job satisfaction. In order to prevent increase in absenteeism among lecturers, the recommendation from respondents was that it was also recommended that government should increase and harmonize lecturers' pay and conditions of service across all tertiary institutions.

\section{Lecturers' Recommendations to College Administrators}

To improve teaching and students' academic performance, the following recommendations were made by the lecturers for the attention of the college administrators. These recommendations included the following:

i. Respondents of the study recommended that Administrators of teacher education institutions should reduce the course loads on both the lecturers and students. Lecturers and students with lesser courses to take per semester the better and more improved teaching and learning outcomes.

ii. It was also recommended that administrators should ensure the timely reviewing and updating of the teaching curriculum. Thus, this should be done according to the educational globalization trends in technology and the changing needs of the country.

iii. Another recommendation made by the respondents was that administrators should ensure and give opportunities to all lecturers to engage in professional development trainings in pedagogy and subject-matter. This, according to the respondents would improve practice.

\section{Researcher's Recommendations}

Based on the results of the study, and to improve teaching and students' achievements, the following recommendations were made by the researcher for consideration by all stakeholders involved in teacher education. These recommendations included:

i. For better academic achievements and quality in teacher education, college administrators and lecturers should ensure to introduce the approach of constructivism, critical thinking and collaborative learning among students in class. This approach is vital for students' research, paper presentations and seminars during the cause of their study, which allow them to own their learning process and outcomes.

ii. For improved participation, punctuality and attendance for classes, administrators should map out policies on absenteeism and punctuality for both staff and students and punitive measures should be taken for defaulter. The policies would help minimize absenteeism, and improve on teaching and students' academic achievements.

iii. For improved teaching and learning outcomes in teacher education, government, nongovernmental organizations, civil societies, the business community and other educational stakeholder should come on board to fund teacher training institutions to better capacitate them for quality teaching and learning processes.

iv. All stakeholders of teacher education should frequently engage in proper monitoring and supervision of these teacher training institutions for quality delivery services.

v. To develop a national quality frame work and policies for all tertiary and teacher training colleges for improved service, teaching, research and students' academic achievement for gainful employability.

\section{REFERENCES}

Armstrong, M. (2012). Armstrong's Handbook of Human Resource Management Practice (12 ${ }^{\text {th }}$ Edition).

Adam, S. (2004). Using Learning Outcome. Retrieved from http://www.aic.lv/ace/ace_disk/Bologna/Bol_ semin/Edinburgh/S_ADam_back_pap.pdf (retrieved, $16^{\text {th }}$ July 2019)

African Union (2006-2015). Second Decade of Education for Africa 2006-2015 Action Plan. Retrieved from, http://www.unesco.org/new/fileadmin/MULTIMEDIA/FIELD/Dakar/pdf/AU\%20SECOND\%20DECADE $\% 200 N \% 20$ EDUCTAION\%202006-2015.pdf (Retrieved 24 ${ }^{\text {th }}$ July 2019) 
ASCD \& EI (2015). The 2030 Sustainable Development Goals and the Pursuit of Quality Education for All: A statement of support from Education International and ASCD. Retrieved from http://www.ascd.org/ASCD /pdf/siteASCD/policy/ASCD-EI-Quality-Education-Statement.pdf Retrieved August 2019.

Cedefop (2017). Defining, writing and applying learning outcomes: a European handbook. Luxembourg publication Office. https://www.cedefop.europa.eu/files/4156_en.pdf

EI Policy Brief. Quality Learning Environment. Retrieved from https://ei-ie.org/media_gallery/Policy brief_01_environment_eng.pdf

Educational Leadership Policy Standards: ISLLC 2008: Retrieved from http://www.epsb.ky.gov/mod/ book/view.php?id=133\&chapterid=83

Gbamanja S.P.T (2010) Report on the Commission of Inquiry into the Poor Performance Retrieved from http:// leonenet.info/documents/COMMISSIONREPORT-RECENT1.pdf

Government of Sierra Leone: Statistic Sierra Leone, 2015 Population census.

GoSL: Education Sector Plan 2018-2020 https://mbsse.gov.sl/wp-content/uploads/2020/02/Educational-SectorPlan-2018-2020.pdf

Harvard Business Essentials: Managing Creativity and Innovation; 2003, HBS press, USA. http://onthe worldmap.com/sierra-leone/ Map of Sierra Leone

Kumar (2016); Teacher Education in India : Some policy Issues and Challenges Retrieved from http://ijariie.com/AdminUploadPdf/Teacher_education_in_India_Some_Policy_issues_and_Challenges_i jariie3514.pdf

Marsh, C.J: Key Concepts for understanding Curriculum, $4^{\text {th }}$ edition, 2009

Overview of quality learning environments: by Peter Smith and Daniel K. Apple: Retrieved from https:// pcrest.com/research/3_1_1\%20Overview\%20of\%20Quality\%20Learning\%20Environments.pdf , accessed $3^{\text {rd }}$ May 2019

Compact Oxford English Dictionary (2005), Oxford University Press, UK.

Sierra Leone Education Country Status Report (2013): An Analysis for further improving the quality, equity and efficiency of education system in Sierra Leone Retrieved from http://www.culture-developpement. asso.fr/wp-content/uploads/2014/02/education-country-status-report-sierra-leonne.pdf

Smith, R.E: Human Resources Administration: A school-based perspective, fourth edition, 2009.

The Glossary of Education Reform: Learning environment, August, 2013: Retrieved from Retrieved https:// www.edglossary.org/learning-environment/, retrieved August 2019.

The Constitution of Sierra Leone, 1991; Retrieved from http://www.sierra-leone.org/Laws/constitution1991.pdf retrieved August 2019

UNESCO (2016): Education for People and Planet: Creating sustainable Futures for All. Retrieved from https://en.unesco.org/gem-report/sites/gem-report/files/GEM_Report_2016_2nd_edition.pdf (Retrieved August 2019)

UNESCO (2014) EFA-GMR Report of 2013/14: Teaching and Learning: Achieving quality for All: Retrieved from https://europa.eu/capacity4dev/education-and-development/document/efa-global-monitoring-report201314-teaching-and-learning-achieving-quality-all

UNESCO (2018): Migration, displacement and Education: Building Bridges, not walls. Retrieved from https:// unesdoc.unesco.org/ark:/48223/pf0000265866/PDF/265866eng.pdf.multi

UNICEF (2000): Defining Quality in education: Retrieved from http://www.oosci-mena.org/uploads/ 1/wysiwyg/Quality_Education_UNICEF_2000.pdf

World Bank (2007): Education in Sierra Leone; Present Challenges, Future Opportunities: Retrieved from http:// documents.worldbank.org/curated/en/618111468166474170/pdf/391660SL0Educa101OFFICIAL0USE0O NLY1.pdf (Retrieved August 2019)

Citation: Prince C. Brainard. "Factors Affecting Quality Teaching and Learning Outcomes in Teacher Education in Sierra Leone” International Journal of Humanities Social Sciences and Education (IJHSSE), vol 8, no. 10, 2021, pp. 94-112. doi: https://doi.org/10.20431/2349-0381.0810010.

Copyright: (C) 2021 Authors. This is an open-access article distributed under the terms of the Creative Commons Attribution License, which permits unrestricted use, distribution, and reproduction in any medium, provided the original author and source are credited. 